\title{
Efecto de la actividad de agua y la temperatura sobre el crecimiento y la esporulación de Aspergillus niger P.E.L. van Tieghem
}

\author{
Effect of water activity and temperature on growth \\ and sporulation of Aspergillus niger P. E. L. van Tieghem
}

Fecha de recepción y aceptación: 23 de febrero de 2021 y 4 de mayo de 2021

DOI: $10.46583 /$ nereis_2021.13.817

\section{F. Sempere-Ferre ${ }^{1 *}$ y M. P. Santamarina ${ }^{2}$}

${ }^{1}$ Departamento de Estadística e Investigación Operativa Aplicadas y Calidad. Universitat Politècnica de València.

* Correspondencia: Universitat Politècnica de València. Departamento de Estadística e Investigación Operativa Aplicadas y Calidad. Camino de Vera s/n. 46022 Valencia. España.E-mail: frasemfe@upvnet.upv.es

${ }^{2}$ Departamento de Ecosistemas Agroforestales. Universitat Politècnica de València.

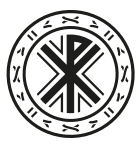

Universidad Católica de Valencia

San Vicente Mártir

\section{RESUMEN}

El efecto de la actividad de agua $(0,85,0,90,0,95,0,98,0,995)$ sobre el crecimiento y la esporulación de Aspergillus niger fue estudiado a distintas temperaturas ( 15 y $25^{\circ} \mathrm{C}$ ). La máxima ratio de crecimiento de la especie se registró a una actividad de agua de 0,98 , y se observó desarrollo en todo el intervalo ensayado salvo a 0,85 y $15^{\circ} \mathrm{C}$. Además, se investigaron sus características morfológicas y culturales en las distintas condiciones de experimentación. A. niger esporuló en casi todas las actividades de agua y temperatura. Ambos factores y su interacción tuvieron un efecto significativo sobre el desarrollo de la especie.

PALABRAS CLAVE: actividad de agua, Aspergillus niger, temperatura, esporulación, ecofisiología fúngica.

\section{ABSTRACT}

The effect of water activity $(0.85,0.90,0.95,0.98,0.995)$ on the growth and sporulation of $A s$ pergillus niger was studied at different temperatures $\left(15\right.$ and $\left.25^{\circ} \mathrm{C}\right)$. Maximum fungal growth rate occurred at water activity of 0.98 , with growth being observed throughout the tested interval except at 0.85 and $15^{\circ} \mathrm{C}$. In addition, morphological and cultural features were studied in the different experimental conditions. This species sporulated at almost all conditions. Both factors and their interaction had a significant effect on the development of the species.

KEYWORDS: water activity, Aspergillus niger, temperature, sporulation, fungal ecophysiology. 


\section{INTRODUCCIÓN}

Aspergillus niger P. E. L. van Tieghem es un hongo ascomiceto, saprófito, filamentoso de reproducción asexual que pertenece a la sección Nigri dentro del género Aspergillus, en el que se han descrito unas 350 especies [1].

La especie destaca por tener un gran interés en la industria farmacéutica, química y alimentaria ya que se utiliza principalmente para la producción de ácidos orgánicos (ácido cítrico, ácido oxálico, ácido glucónico), enzimas (poligalacturonasa, polimetilgalacturonasa, pectinliasa, pectinesterasa) y otros compuestos bioactivos con aplicaciones diversas [2-4].

En la naturaleza, es un hongo ampliamente distribuido, característico de zonas climáticas templadas, que ha sido aislado de una amplia variedad de sustratos entre los que se encuentran frecuentemente los cereales, entre ellos, el arroz.

Durante el almacenamiento, $A$. niger junto con otras especies pertenecientes a distintos géneros son las responsables del deterioro del cereal. Su aparición tiñe el grano de una coloración negruzca, produciendo, además, una inhibición de la germinación, calentamiento, amohosado, apelmazado y finalmente la pudrición de la semilla. Además, fruto de su metabolismo secundario, se pueden producir diversos compuestos como la ocratoxina $\mathrm{A}$ y las fumonisinas que pueden generar a largo plazo efectos adversos en el ser humano [5].

La presencia del hongo generalmente es más numerosa en los granos rotos o descascarados, por lo que constituyen centros potenciales de infección cuando se verifican las condiciones de humedad y temperatura propicias para su desarrollo.

El objetivo principal de este estudio fue investigar el efecto de la actividad de agua sobre el crecimiento y la esporulación de Aspergillus niger a distintas temperaturas. Al mismo tiempo se estudiaron los caracteres morfológicos y culturales de la especie en las condiciones ensayadas.

\section{MÉTODOS}

\section{Aislado y medio de cultivo}

Aspergillus niger fue aislada en el laboratorio de Biología Vegetal del Departamento de Ecosistemas Agroforestales de la Universitat Politècnica de València de muestras de granos de arroz con un periodo de almacenamiento de 9 meses.

El medio de cultivo utilizado para el ensayo fue agar extracto de arroz (AEA), que se obtuvo a partir de granos de arroz cáscara. Los distintos valores de agua experimentados $(0,85,0,90,0,95,0,98$ y 0,995$)$ se consiguieron añadiendo al medio distintas cantidades de glicerol [6].

\section{Inoculación y medida del crecimiento individual}

En total se realizaron 10 tratamientos combinando 5 actividades de agua $(0,85,0,90,0,95,0,98$, $0,995)$ y dos temperaturas $\left(15\right.$ y $\left.25^{\circ} \mathrm{C}\right)$. 
Para el estudio macroscópico, en cada una de las placas se inocularon en el centro discos de $8 \mathrm{~mm}$ de diámetro obtenidos de la periferia de colonias puras de A. niger crecidas en agar patata dextrosa (PDA) a $25^{\circ} \mathrm{C}$ durante 5 días, y se incubaron en las mismas condiciones durante una semana.

El experimento se repitió cinco veces. El crecimiento fue registrado diariamente mediante la medición por colonia fúngica de dos diámetros perpendiculares. Para calcular la ratio de crecimiento $(\mathrm{mm}$ día $^{-1}$ ) se realizó una regresión lineal de los radios $(\mathrm{mm})$ frente al tiempo (días). El programa utilizado fue Excel 2016 (Microsoft, EE. UU.).

Al final y durante este periodo, se observaron los cultivos a simple vista o con ayuda de una lupa y se registraron las características culturales.

\section{Ensayo microscópico}

Para el análisis de la especie con el microscopio electrónico de barrido de bajas temperaturas, una suspensión de esporas se sembró en cuadrados de agar de extracto de arroz de $1 \mathrm{~cm}$ y se incubó a las distintas temperaturas y actividades de agua durante 5 días. El estudio en el microscopio óptico se realizó adaptando la técnica del microcultivo descrita por García de Lomas, en las mismas condiciones de experimentación [7].

\section{Análisis estadístico}

Para verificar la influencia de los factores $a_{\mathrm{w}}$, temperatura (T), así como sus interacciones sobre el crecimiento fúngico de la especie, se realizó el test de análisis de la varianza (ANOVA) con valores de significación de $\mathrm{P}<0,01$. El programa utilizado fue Statgraphics Centurion XVII (Stat Point, Inc., Herndon, Virginia, EE. UU.).

\section{RESULTADOS}

\section{Caracteres culturales}

Macroscópicamente, A. niger formó en todas las temperaturas y actividades de agua ensayadas colonias blanquecinas con una textura aterciopelada, en las que se apreciaron al cabo de una semana las cabezas conidiales negras dispuestas irregularmente o formando círculos concéntricos alrededor del inóculo inicial a $0,995,0,98$ y 0,95 a $25^{\circ} \mathrm{C}$ (figura 1). El reverso también fue blanquecino, muchas veces difícil de distinguir de no ser por las cabezas conidiales.

\section{Ratios de crecimiento}

A ambas temperaturas, el máximo crecimiento de $A$. niger se produjo a una actividad de agua de 0,98 , siendo las ratios de crecimiento de $5,78 \mathrm{~mm} \cdot$ día $^{-1}$ a $25^{\circ} \mathrm{C}$ y $1,78 \mathrm{~mm} \cdot$ día $^{-1}$ a $15^{\circ} \mathrm{C}$ (figura 2). 
Además, a 0,995 y $0,95 a_{\mathrm{w}}$ las ratios de crecimiento fueron muy similares, sin que se registrara casi variación. Sin embargo, durante los cinco días de medición solo se observó crecimiento a $25^{\circ} \mathrm{C}$ en todas las actividades de agua ensayadas, pero no a $15^{\circ} \mathrm{C}$, ya que a $0,85 a_{\mathrm{w}}$ este fue nulo.

El desarrollo de la especie siempre fue mayor a $25^{\circ} \mathrm{C}$ que a $15^{\circ} \mathrm{C}$ en todas las actividades de agua ensayadas.

La $a_{\mathrm{w}}$ y T tuvieron un efecto significativo sobre el crecimiento de $A$. niger $(\mathrm{P}<0,01)$ (tabla 1$)$. Al analizar los gráficos LSD de comparación de medias de la actividad de agua y temperaturas, se observó que estas diferencias fueron significativas entre la actividad de agua de 0,90 y 0,95 y entre $25^{\circ} \mathrm{C}$ y $15^{\circ} \mathrm{C}$ (datos no mostrados).

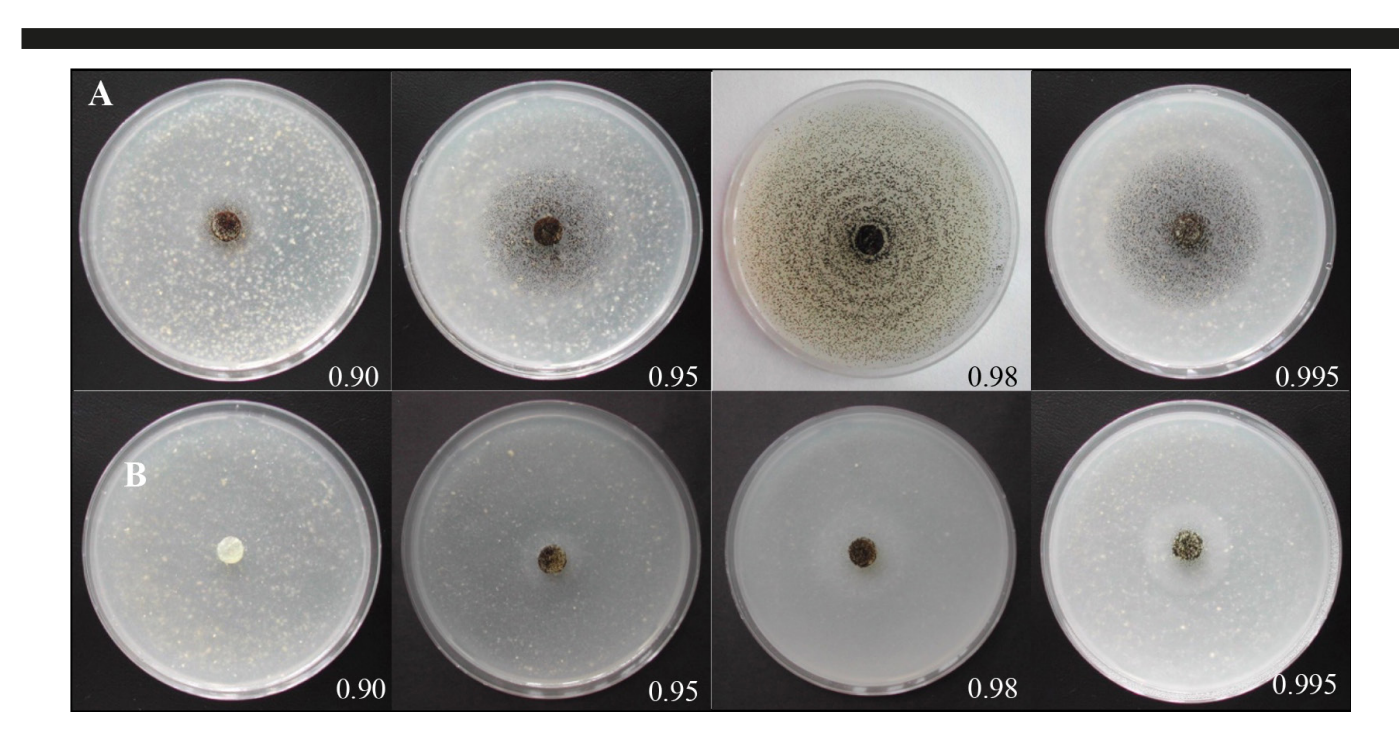

Fig. 1. Colonias de siete días de $A$. niger crecidas a distintas actividades de agua y temperaturas. Fila A: $25^{\circ} \mathrm{C}$. Fila B: $15^{\circ} \mathrm{C}$. Fuente: elaboración propia.

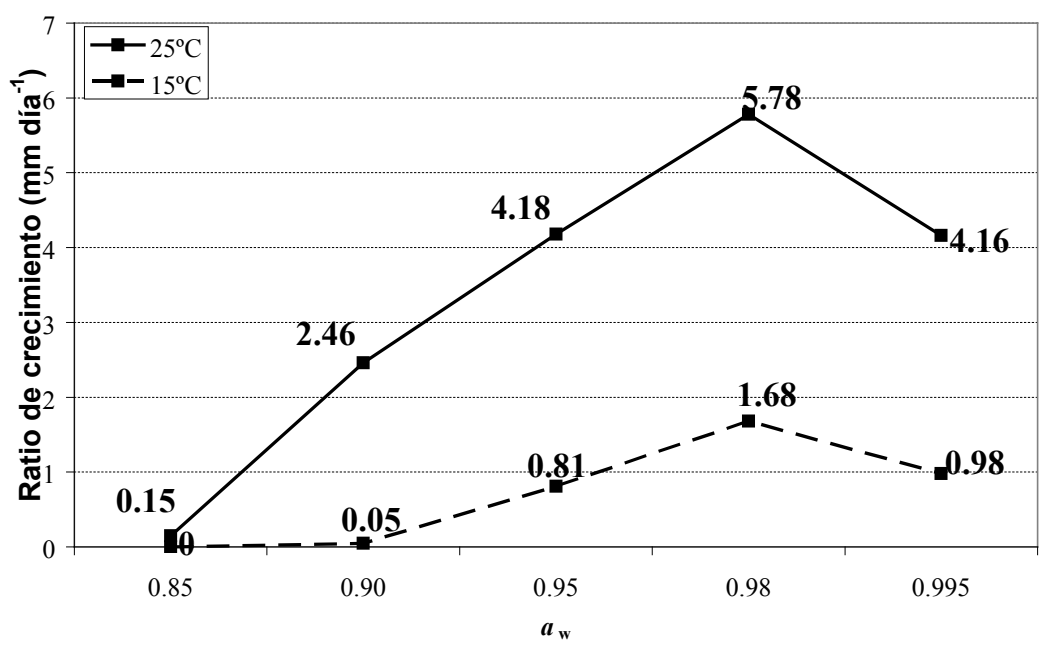

Fig. 2. Influencia de la actividad de agua sobre la ratio de crecimiento de $A$. niger en AEA en función de la temperatura 
Tabla 1. Análisis de la varianza del crecimiento de A. niger; significancia de los factores actividad de agua $\left(a_{\mathrm{w}}\right)$, temperatura $(\mathrm{T})$ y su interacción $\left(a_{\mathrm{w}} \mathrm{x} \mathrm{T}\right)$. $* * \mathrm{P}<0,01$

\begin{tabular}{ccccc}
\hline Factor & GL & CM & F-ratio & P-valor \\
\hline$a_{\mathrm{w}}$ & 4 & 541,941 & 32,32 & $0,0000^{* *}$ \\
$\mathrm{~T}$ & 1 & 2566,86 & 153,10 & $0,0000^{* *}$ \\
$a_{\mathrm{w}} \times \mathrm{T}$ & 4 & 235,09 & 14,02 & $0,0000^{* *}$ \\
\hline
\end{tabular}

\section{Caracteres morfológicos}

Microscópicamente esta especie mostró hifas septadas hialinas con conidióforos de pared lisa. Cabeza conidial globosa o subglobosa con métulas y fiálides a partir de las cuales nacían las esporas asexuales. Conidios globosos o subglobosos de pared rugosa y que presentaban una especie de protuberancias entrelazadas (figura 3).

A. niger esporuló en todas las temperaturas y actividades de agua, descartándose su estudio a 0,85 $a_{\mathrm{w}}$ por ser el crecimiento mínimo o nulo. A $0,98 a_{\mathrm{w}}$ y $25^{\circ} \mathrm{C}$ el número de esporas observadas fue mayor.

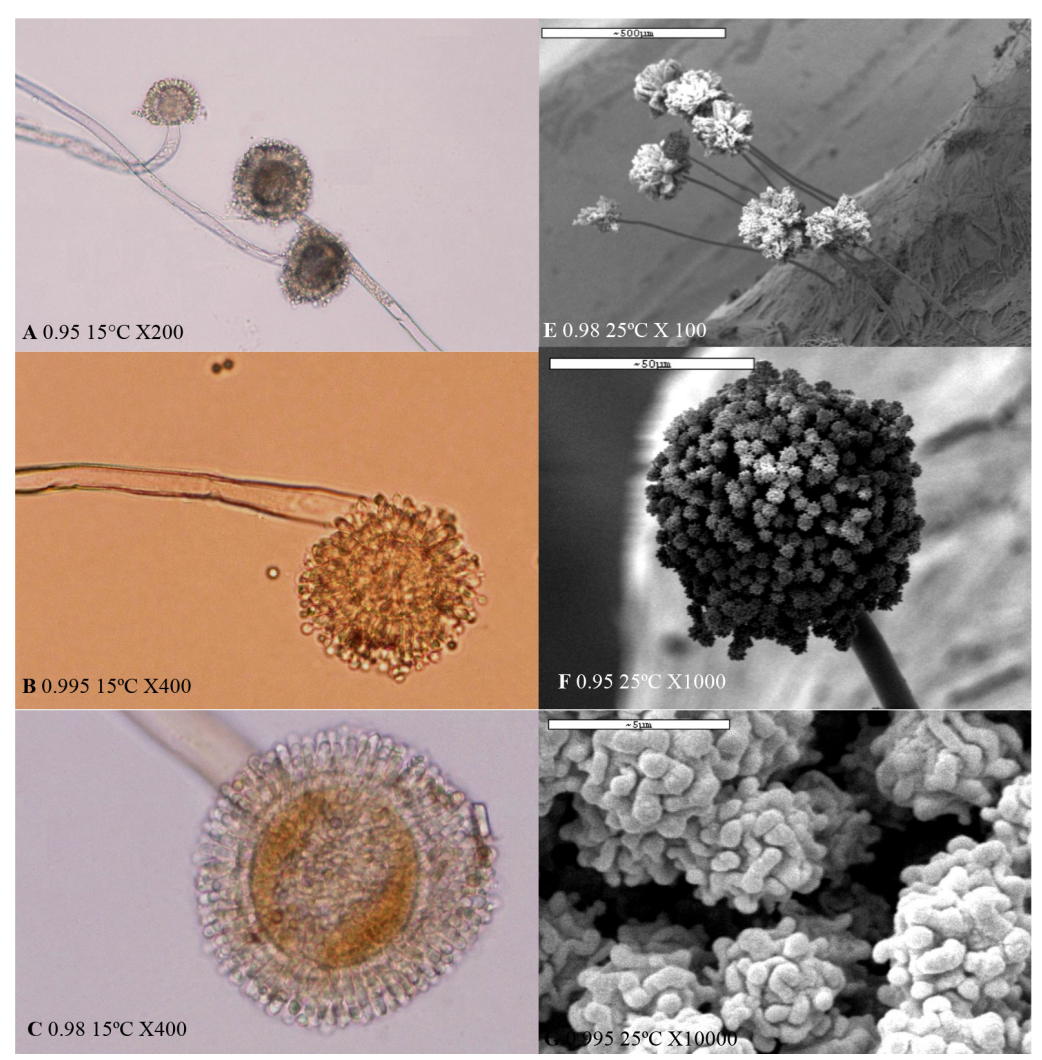

Fig. 3. Micrografías de microscopía óptica (LM) y microscopía electrónica de barrido de bajas temperaturas (Cryo-SEM) de $A$. niger a distintas temperaturas y actividades de agua. A, B, C, D, E, F: Conidióforos y cabezas conidiales. G: Conidios. Fuente: elaboración propia. 


\section{DISCUSIÓN}

Este ensayo realizó un estudio ecofisiológico de la especie Aspergillus niger a distintas temperaturas y actividades de agua en agar extracto de arroz.

La actividad de agua óptima registrada para la especie fue de 0,98 . En un estudio donde el hongo se inoculó en agar extracto de malta en las que las distintas actividades de agua $(0,90-0,99)$ se regularon con glicerol y NaCl, su crecimiento óptimo se produjo a unos valores de actividad de agua de 0,93 y 0,95 respectivamente [8]. Astoreca et al. obtuvieron que el mayor desarrollo de la especie se produjo a $0,97 a_{\mathrm{w}}$ y $30^{\circ} \mathrm{C}$ cuando se inoculó en medios obtenidos a partir de cacahuetes, granos de maíz, uvas secas y semillas de café [9]. En otros ensayos el hongo mostró unas actividades de agua óptimas de 0,995 a $30^{\circ} \mathrm{C}, 0,98$ a $35^{\circ} \mathrm{C}$ y 0,95 a $28^{\circ} \mathrm{C}$ cuando creció sobre Czapek con extracto de levadura, un medio sintético obtenido a partir de jugo de uva y otro elaborado a partir de cebada [10-12].

La especie mostró un mayor desarrollo fúngico a $25^{\circ} \mathrm{C}$. Para este hongo se han descrito temperaturas óptimas de $25-44^{\circ} \mathrm{C}, 30^{\circ} \mathrm{C}$ y $37^{\circ} \mathrm{C}$ en maíz y en otros medios naturales y sintéticos $[9,11,13,14]$.

Aspergillus niger se desarrolló en todas las actividades de agua experimentadas salvo a $0,85 a_{\mathrm{w}}$ a $15^{\circ} \mathrm{C}$. Previos estudios han obtenido rangos de crecimiento de la especie de $0,77-0,99,0,86-0,99$ en diferentes medios de cultivo [15].

El hongo esporuló en todas las condiciones ensayadas. En agar extracto de malta se observó que la formación de conidios fue más abundante a 0,97 y a $35^{\circ} \mathrm{C}[8]$.

La mínima actividad de agua de desarrollo se produjo a 0,85 . Esta misma actividad fue registrada en un ensayo realizado previamente, pero Marin et al., al igual que en la presente investigación, obtuvieron que la actividad mínima de crecimiento a $15^{\circ} \mathrm{C}$ fue de $0,90 a_{\mathrm{w}}[9,14]$.

Los factores ecofisiológicos de actividad de agua, temperatura y su interacción tuvieron un efecto significativo sobre el desarrollo de la especie, coincidiendo los resultados obtenidos con otras investigaciones [8-12,16,17].

Aspergillus niger se muestra como un hongo xerofítico capaz de crecer en una amplia variedad de condiciones. Su desarrollo viene determinado por diferentes factores intrínsecos a la especie como extrínsecos. Conocer estos factores es fundamental para poder establecer estrategias futuras de control.

\section{REFERENCIAS BIBLIOGRÁFICAS}

[1] De Vries RP, Riley R, Wiebenga A, Aguilar-Osorio G, Amillis S, Uchima CA, et al. Comparative genomics reveals high biological diversity and specific adaptations in the industrially and medically important fungal genus Aspergillus. Genome Biol. 2017;18.

[2] Behera BC. Citric acid from Aspergillus niger: a comprehensive overview. Critical Reviews in Microbiology. 2020;46:727-49.

[3] Li C, Zhou J, Du G, Chen J, Takahashi S, Liu S. Developing Aspergillus niger as a cell factory for food enzyme production. Biotechnology Advances. 2020;44:107630.

[4] Differences in metabolites production using the Biolog FF Microplate ${ }^{\mathrm{TM}}$ system with an emphasis on some organic acids of Aspergillus niger wild type strains. Biologia - X-MOL n. d. (consultado: 23 enero 2021). Disponible en: https://www.X-mol.com/paper/1263906105200844800 
[5] Perrone G, Gallo A. Aspergillus species and their associated mycotoxins. In: Moretti A, Susca A, editors. Mycotoxigenic fungi: methods and protocols. New York, NY: Springer; 2017, pp. 33-49.

[6] Sempere F, Santamarina MP. In vitro biocontrol analysis of Alternaria alternata (Fr.) Keissler under different environmental conditions. Mycopathologia. 2007;163:183-90.

[7] García de Lomas J, Marín F, Altuna A, Cuadrado E. A simple and rapid method for microculture and identification of fungi. Mycopathologia. 1981;76:119-24.

[8] Parra R, Aldred D, Archer DB, Magan N. Water activity, solute and temperature modify growth and spore production of wild type and genetically engineered Aspergillus niger strains. Enzyme and Microbial Technology. 2004;35:232-7.

[9] Astoreca A, Magnoli C, Ramirez ML, Combina M, Dalcero A. Water activity and temperature effects on growth of Aspergillus niger, A. awamori and A. carbonarius isolated from different substrates in Argentina. Int J Food Microbiol. 2007;119:314-8.

[10] Leong SL, Hocking AD, Scott ES. Effect of temperature and water activity on growth and ochratoxin A production by Australian Aspergillus carbonarius and A. niger isolates on a simulated grape juice medium. Int J Food Microbiol. 2006;110:209-16.

[11] Gerez CL, Dallagnol A, Ponsone L, Chulze S, Font de Valdez G. Ochratoxin A production by Aspergillus niger: Effect of water activity and a biopreserver formulated with Lactobacillus plantarum CRL 778. Food Control. 2014;45:115-9.

[12] Lasram S, Hamdi Z, Chenenaoui S, Mliki A, Ghorbel A. Comparative study of toxigenic potential of Aspergillus flavus and Aspergillus niger isolated from Barley as affected by temperature, water activity and carbon source. Journal of Stored Products Research. 2016;69:58-64.

[13] Alborch L, Bragulat MR, Abarca ML, Cabañes FJ. Effect of water activity, temperature and incubation time on growth and ochratoxin A production by Aspergillus niger and Aspergillus carbonarius on maize kernels. Int J Food Microbiol. 2011;147:53-7.

[14] Marin S, Sanchis V, Ramos AJ, Vinas I, Magan N. Environmental factors, in vitro interactions, and niche overlap between Fusarium moniliforme, F. proliferatum, and F. graminearum, Aspergillus and Penicillium species from maize grain. Mycological Research. 1998;102:831-7.

[15] Esteban A, Abarca ML, Bragulat MR, Cabañes FJ. Effect of water activity on ochratoxin A production by Aspergillus niger aggregate species. Int J Food Microbiol. 2006;108:188-95.

[16] Parra R, Magan N. Modelling the effect of temperature and water activity on growth of Aspergillus niger strains and applications for food spoilage moulds. J Appl Microbiol. 2004;97:429-38.

[17] Palacios-Cabrera H, Taniwaki MH, Hashimoto JM, Menezes HC de. Growth of Aspergillus ochraceus, A. carbonarius and A. niger on culture media at different water activities and temperatures. Brazilian Journal of Microbiology. 2005;36:24-8. 